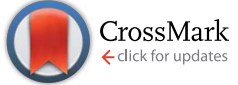

Cite this: RSC Adv., 2017, 7, 67

Received 11th November 2016 Accepted 6th December 2016

DOI: 10.1039/c6ra26676b

www.rsc.org/advances

\section{A liposome-actuated enzyme system and its capability as a self-biomineralized silica nanoreactor $\dagger$}

\author{
S. Municoy and M. G. Bellino* \\ Controlling the functions that arise in biomolecular nanostructures is a major challenge in biotechnology \\ developments. Liposomes have been used to encapsulate a wide variety of enzymes, but the emergent \\ properties of systems in which enzymatic activity is controlled by surrounding liposomes have not been \\ explored. Here, we report an assembly to actuate the reactivity of ureases through the change of the \\ liposome permeability by means of temperature control. Using this approach, externally controlled \\ enzyme inhibition and activation are successfully demonstrated. Furthermore, deposited on a sacrificial \\ mesoporous thin film, this biosystem controllably rebuilds its surface to generate a 3D silica shell, which \\ provides an additional demonstration to the proposed principle.
}

Artificial nanoreactors are appealing as a way to gain insight into biological compartmentalization and for vast applications in medicine and biotechnology ${ }^{1-3}$ Nature uses molecular selfassembly to construct containers with well-defined barriers as functional structures. ${ }^{4,5}$ At their most basic, these structures consist of a semipermeable interface through which reactants and products can pass and an interior catalytic machinery where reactions occur. A notable example of compartments that have been used as nanoreactors are the phospholipid vesicles (liposomes) that confine active enzymes. ${ }^{6}$ Thus far, research on this extensively studied class of carrier has focused on their enhanced enzyme stability as well as functional vehicles to deliver the enzymes..$^{7-9}$ Among addressable nanoscale systems, thermo-liposomes stand out for their ability to convert a thermal input into a change in liposome characteristics. These thermal switches can be used to modulate the properties of vesicles at the interface level, such as membrane permeability, thereby externally modulating molecule flow and, by extension, drug release. ${ }^{10-12}$ The ability to regulate enzyme activity in response to remote control is critical to many enzymatic applications. In this context, a particularly challenging and appealing application of these thermo-switches would be gating enzymatic systems. With this in mind, our approach has been to append these addressable thermosensitive gates to a naturally occurring enzyme reaction. One of the bestcharacterized proteins is the urease. In nature, this enzyme functions as an entity to catalyze hydrolysis of urea. ${ }^{13} \mathrm{An}$ influx

Comisión Nacional de Energía Atómica, CONICET, Departamento de Micro y Nanotecnología, Av. Gral. Paz 1499, 1650, Argentina. E-mail: mbellino@cnea.gov.ar $\dagger$ Electronic supplementary information (ESI) available: Experimental section, the control experiments and further characterization of the liposome-templates and mesoporous films. See DOI: 10.1039/c6ra26676b of urea results in its breakdown into carbon dioxide and ammonia, raising the $\mathrm{pH}$ in the solution. ${ }^{14}$ Here, we demonstrate a controlled enzyme inhibition and activation through encapsulation of ureases into thermo-liposomes. In a separate but related thread, the fabrication of bioinspired nanometersized materials has gained considerable attention because of their potential uses in both biomaterial research and the development of dynamic nanomaterials as well as fundamental new insights on biomineralization. ${ }^{15-18}$ Herein, as proof of concept, we describe a biomimetic approach in which placement of the thermo-liposome/urease assembly onto a mesoporous silica film leads to partial dissolution of matrix components and controlled enzymatic reconstruction of a 3D interface composed of silica shells on liposomes.

Lipid vesicles of required composition and size were obtained by the lipid film hydration and extrusion method. ${ }^{6,19,20}$ When a lipid film, DPPC/cholesterol $1: 0.2$ in composition, was hydrated and extruded through polycarbonate membranes with a $2 \mathrm{mg} \mathrm{ml}^{-1}$ urease solution, $410 \mathrm{~nm}$ in diameter nanoreactors were formed in which enzymes are entrapped by lipid vesicles (see ESI Fig. S1 $\dagger$ ). The calculated efficiency for enzyme loading was $12 \%$ of the soluble enzyme. With temperature approaching to the gel-to-fluid phase transition temperature $\left(T_{\mathrm{m}}\right)$, liposome membrane is consequently more permeable. ${ }^{6,19}$ The $T_{\mathrm{m}}$ of vesicles was seen at approximately $40{ }^{\circ} \mathrm{C}$, in agreement with literature values ${ }^{21,22}$ (see ESI Fig. S1 $\dagger$ ). In order to test the utility of the thermo-addressable liposomes in controlling enzymatic reactions, we conducted classical experiments by performing a urease hydrolysis reaction using a $\mathrm{pH}$ sensitive probe (see Fig. S2 in ESI $\dagger$ ). The urease biocatalyses the hydrolysis of urea, causing the deprotonation of the yellowish bromothymol blue (BTB) to the bluish product, $\mathrm{BTB}^{-}=617 \mathrm{~nm}^{.23,24}$ Direct 
measurements of this capability were difficult because of the dependence of enzymatic activity on temperature (see Fig. S3†). To solve this, Fig. 1a illustrates the experimental design, where platforms composed of liposomes and free ureases (active + desnaturalized) with the same activity at $T<T_{\mathrm{m}}\left(25^{\circ} \mathrm{C}\right)$ and $T>T_{\mathrm{m}}$ $\left(45^{\circ} \mathrm{C}\right)$ were compared to equivalent assemblies of liposomes entrapping ureases. Fig. $1 \mathrm{~b}$ depicts the rates of $\mathrm{BTB}^{-}$formation in the presence of the free enzyme/liposome state at $25^{\circ}$ and $45{ }^{\circ} \mathrm{C}$, respectively. Evidently, the same urease system activity at both temperatures was obtained in the free enzyme condition.

Fig. 1c illustrates the functional operation of the thermoliposomes on the entrapped ureases: curves at $25^{\circ}$ and $45{ }^{\circ} \mathrm{C}$ show the time-dependent formation of $\mathrm{BTB}^{-}$using the enzyme/ liposome assembly, respectively. In fact, the results in Fig. 1c vividly demonstrate the ability of the temperature input to regulate enzymatic activity by switching between on/off states of liposome-entrapping enzymes. The entrapped ureases showed a faster and sensitive response to urea at $T>T_{\mathrm{m}}$, reaching up to $50 \%$ of the maximum steady-state hydrolysis in approximately $20 \mathrm{~min}$. In contrast, hardly any activity was detected at $T<T_{\mathrm{m}}$. The activity value at $25{ }^{\circ} \mathrm{C}$ was 10 times lower than at $45^{\circ} \mathrm{C}$. A pronounced induction period can in addition be noted for samples at $25{ }^{\circ} \mathrm{C}$. These data provide evidence that the enzymatic activity was effectively reduced by diffusional effects, which arise from the liposome permeability. ${ }^{23}$ Therefore, these structures provide controllable environments that regulate flow of reactants, applicable to control enzyme activity, as demonstrated with a urease/liposome assembly that can function as a switchable bioreactor.

Having achieved the conversion of the urease into a biocatalyst actuated by temperature, we set out to exploit the

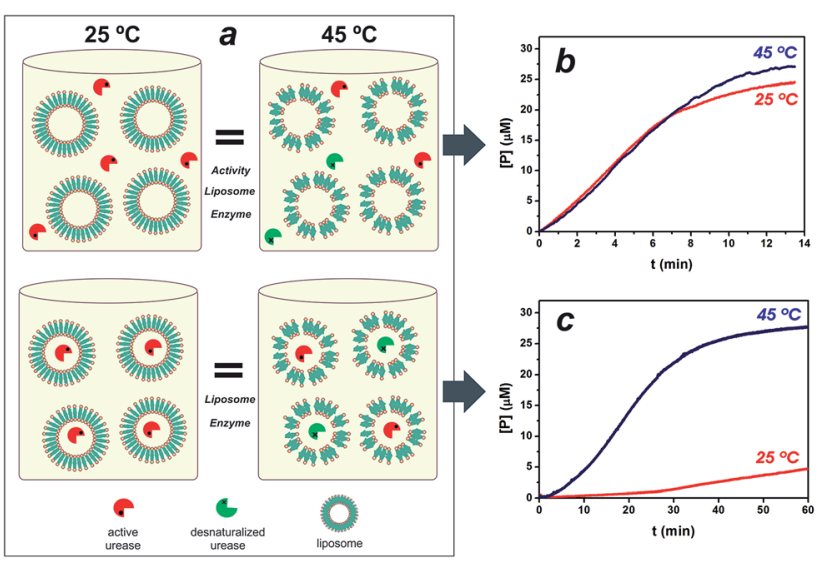

Fig. 1 Artificial microreactor control. Schematic drawing of the experimental design and its components (a). Active and desnaturalized enzymes have been drawn with different colors for clarity. The free enzyme/liposome state and the assembly of the system are shown at the top and bottom respectively. It is worth mentioning that the different states are equivalent in respect to all components (amount of enzymes and liposomes) and the same activity for the free enzyme condition at both temperatures is obtained. The kinetic response of urea degradation by free ureases with the liposome scaffold and their corresponding encapsulated enzyme condition are shown (b and $c$ respectively). enzymatic $\mathrm{pH}$ thermo-control in the biomimetic synthesis of silica structures. The silica precipitation proposed process is depicted in Fig. 2. Upon introduction of an aqueous suspension (pH 5) of urea and urease/liposomes onto a mesoporous silica thin film ${ }^{25,26}$ (140 $\mathrm{nm}$ thick, 50\% porous, $7 \mathrm{~nm}$ pore diameter, see Fig. S4 in ESI $\dagger$ ), silica component of the film is solubilized by the droplet (Fig. 2a). Mesoporous silica films present a rapid degradation, making them suitable candidates as silicon source. ${ }^{27}$ As evaporation proceeds, urea, urease/liposomes and soluble silica is progressively concentrated within the droplet (Fig. 2b). At this stage, urease/liposomes develop a localized three-dimensional gradient in $\mathrm{pH}$, catalyzing silica condensation, and their self-templated in a 3D silica nanostructure (Fig. 2c). As the rate of silica condensation is function of $\mathrm{pH}^{28}$ it is expected that the development of the localized $\mathrm{pH}$ gradient leads liposome self-encapsulation within silica. Rinsing the substrate shortly after droplet evaporation removes uncondensed silica, obtaining liposomes encapsulated in a silica shell (Fig. 2d).

By carefully tuning the synthesis conditions, we obtained samples that consisted mainly of spherical particles with a narrow size distribution in the $T<T_{\mathrm{m}}$ condition $\left(25{ }^{\circ} \mathrm{C}\right)$. However, the particles had aggregated into lumps (see Fig. 3a),
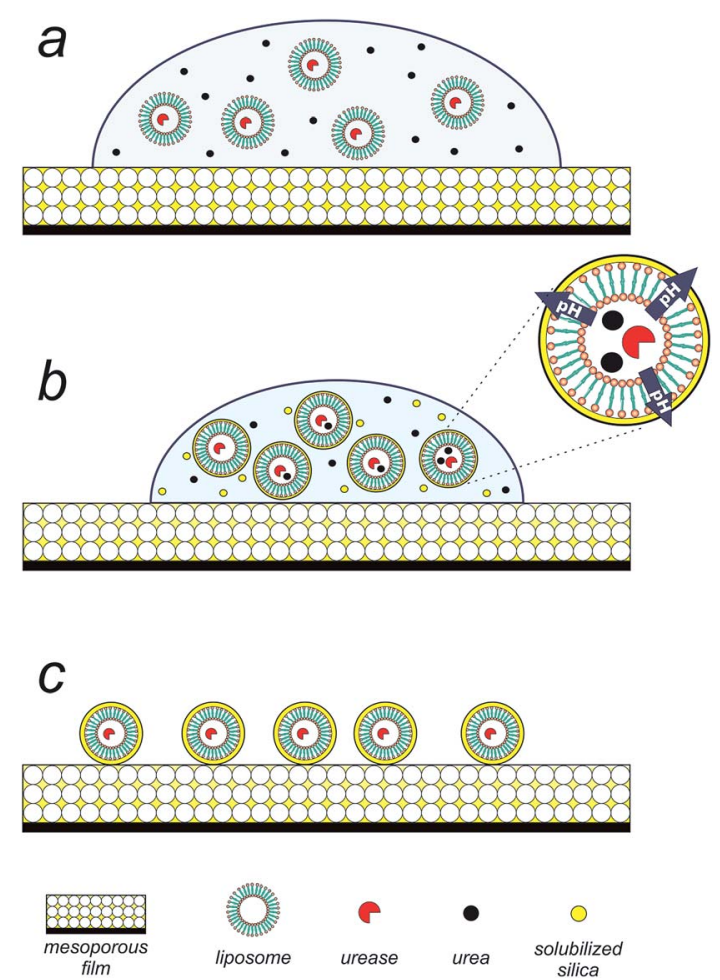

Fig. 2 Precipitation of silica on preformed liposomes occurs via (a) solubilization of the mesoporous silica thin films upon placement of an aqueous droplet containing urea and the urease/liposome assembly. (b) Droplet evaporation leads to concentrate liposomes and soluble components. Liposomes entrapping ureases create a locally higher $\mathrm{pH}$, catalyzing silica condensation and a self-templating of a 3D lipid/ silica nanostructure. (c) Rinsing the substrate following droplet evaporation removes excess of urea and noncondensed silica, yielding liposomes enveloped in a silica shell. 
probably due to condensation of surface groups of different spheres when they came into contact with each other. This aggregation can be avoided if the synthesis mixture is diluted. Using such a procedure, we produced exclusively isolated particles. Fig. 3b and c, which present SEM and TEM micrographs of this condition, show that uniform spheres having an average diameter of $570 \mathrm{~nm}$ were obtained, in close comparison with the starting liposomes. From these results we can estimate a thickness of approximately $80 \mathrm{~nm}$ of the silica shells. Importantly, the particles prepared at the present experimental conditions maintain their individuality, as it is evident from Fig. 3b. The few cracked capsules show the silhouette of the inorganic shells (Fig. 3c), yet they are stable enough to outlast drying and vacuum when the sample was prepared for electron microscopy. Temperature was the mechanism for controlling enzymatic activity ( $\mathrm{pH}$ gradient) through membrane permeability and was crucial in the formation of nanostructured silica. Under low temperature $\left(T<T_{\mathrm{m}}\right)$ structures with predominantly spherical morphologies were observed, which reflects the size and shape of the liposomes because the silica solidifies around them. In contrast, with increasing temperature to $T>T_{\mathrm{m}}\left(45^{\circ} \mathrm{C}\right)$ the spherical morphology disappears completely, indeed, only some large shapeless particles were observed (Fig. S5a $\dagger$ ). Evidence that the integration process is actively directed by encapsulated enzyme system is presented in Fig. S5b, $\dagger$ where we substituted the liposomes entrapping ureases for the free urease/liposome system used in the previous experiments. As shown in Fig. S5b, $\uparrow$ in both temperature conditions, no controlled precipitation was observed. Together, these results illustrate that liposome-silica integration is attributable to the ability of system at $T<T_{\mathrm{m}}$ to actively develop a favourable $\mathrm{pH}$ gradient that catalyses silica
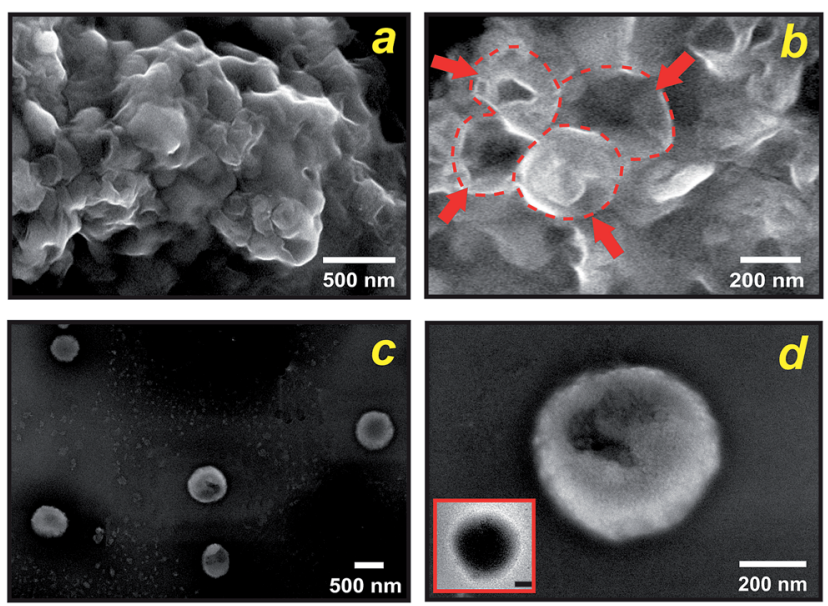

Fig. 3 Shell morphologies. Dependence of the morphology of the precipitates on the mixture concentration, as seen in SEM images. At high concentration (3 $\mathrm{mg} \mathrm{ml}^{-1}$ DPPC) aggregated spherical particles are formed, the arrows and dotted lines indicate the presence of welldefined silica-cast vesicles ( $a$ and $b$ ); whereas at lower concentration (0.8 $\mathrm{mg} \mathrm{m}^{-1}$ DPPC) the particles are isolated (c). SEM image of a cracked hollow sphere show the silhouette of the inorganic shell $(d)$. The inset shows a representative TEM micrograph (scale bar $=100 \mathrm{~nm}$ ). condensation within a three-dimensional volume surrounding the liposome.

There has been considerable success with the formation of silica structures created by liposome-templating strategies, ${ }^{29,30}$ but, to our knowledge, the literature does not report works concerning liposome-actuating enzyme systems for achieving controlled self-biomineralization of silica nanostructures as those used in the present work.

In summary, the present study has introduced the use of thermo-liposomes for the control of enzymatic activity. The encapsulation of the ureases leads to the ability to turn on and off the activity of enzymes by means of thermo-control that does not proceed in an equivalent free enzyme system. In the $T<T_{\mathrm{m}}$ state the limited liposome-membrane permeability inhibits the activity of the urease by holding the urea apart, while in the $T>$ $T_{\mathrm{m}}$ state the improved urea diffusion results in greatly enhanced activity. This novel approach may have technological as well as fundamental implications. In order to test the utility of the liposome-addressable urease activity in controlling biomineralization, we conducted a unique approach in which enzyme/liposome assembles deposited on a sacrificial mesoporous silica film actively reconstructs its surface to create a fully 3D silica shell that interfaces the liposomes. The liposome-actuated enzymatic activity principle was key to obtain controlled silica structures. It is by now almost certain that interfaces play a crucial role in biomineralization, and the interplay of control on enzymatic activity and membrane permeability is certainly necessary to develop intricate structures such as diatoms.

Considering the vast library of enzymes that are currently or potentially available, in the future it may be feasible to develop responsive enzyme-nanoreactors for a broad range of biotechnology applications. With additional developments in liposome/enzyme attachment it should be possible to introduce feedback or feed-forward control loops.

\section{Acknowledgements}

This work was supported by ANPCyT (PICT 2969). SM acknowledges CONICET for a doctoral scholarship. We thank to G. Zbihlei of Lab. de Microscopía Electrónica-Gerencia Materiales-CNEA for TEM image. We thank Dr A. Wolosiuk for assistance with DLS measurements.

\section{Notes and references}

1 C. E. Ashley, E. C. Carnes, G. K. Phillips, D. Padilla, P. N. Durfee, P. A. Brown, T. N. Hanna, J. Liu, B. Phillips and M. B. Carter, Nat. Mater., 2011, 10, 389.

2 D. Peer, J. M. Karp, S. Hong, O. C. Farokhzad, R. Margalit and R. Langer, Nat. Nanotechnol., 2007, 2, 751.

3 V. Wagner, A. Dullaart, A.-K. Bock and A. Zweck, Nat. Biotechnol., 2006, 24, 1211.

4 S. Kang and T. Douglas, Science, 2010, 327, 42.

5 G. M. Whitesides, Nat. Biotechnol., 2003, 21, 1161.

6 P. Walde and S. Ichikawa, Biomol. Eng., 2001, 18, 143.

7 V. P. Torchilin, Nat. Rev. Drug Discovery, 2005, 4, 145. 
8 G. Gregoriadis and R. A. Buckland, Nature, 1973, 244, 170.

9 B. Chatin, M. Mével, J. Devallière, L. Dallet, T. Haudebourg,

P. Peuziat, T. Colombani, M. Berchel, O. Lambert and

A. Edelman, Mol. Ther.-Nucleic Acids, 2015, 4, e244.

10 X. Guo and F. C. Szoka, Acc. Chem. Res., 2003, 36, 335.

11 S. Langereis, J. Keupp, J. L. van Velthoven, I. H. de Roos,

D. Burdinski, J. A. Pikkemaat and H. Grüll, J. Am. Chem. Soc., 2009, 131, 1380.

12 M. de Smet, S. Langereis, S. van den Bosch and H. Grüll, J. Controlled Release, 2010, 143, 120.

13 E. Jabri, M. B. Carr, R. P. Hausinger and P. A. Karplus, Science, 1995, 268, 998.

14 H. Mobley, M. D. Island and R. P. Hausinger, Microbiol. Rev., 1995, 59, 451.

15 J. D. Hartgerink, E. Beniash and S. I. Stupp, Science, 2001, 294, 1684.

16 M. Sumper and E. Brunner, Adv. Funct. Mater., 2006, 16, 17. 17 L. C. Palmer, C. J. Newcomb, S. R. Kaltz, E. D. Spoerke and S. I. Stupp, Chem. Rev., 2008, 108, 4754.

18 C. Li and L. Qi, Angew. Chem., 2008, 47, 2388.

19 S. Municoy and M. G. Bellino, ChemistrySelect, 2016, 1, 723.
20 M.-S. Martina, J.-P. Fortin, C. Ménager, O. Clément, G. Barratt, C. Grabielle-Madelmont, F. Gazeau, V. Cabuil and S. Lesieur, J. Am. Chem. Soc., 2005, 127, 10676.

21 L. Redondo-Morata, M. I. Giannotti and F. Sanz, Langmuir, 2012, 28, 12851.

22 X. Xu, A. Costa and D. J. Burgess, Pharm. Res., 2012, 29, 1919.

23 Y. Lvov, A. A. Antipov, A. Mamedov, H. Möhwald and G. B. Sukhorukov, Nano Lett., 2001, 1, 125.

24 E. Goldman and L. H. Green, Practical Handobook of Microbiology, CRC Press, Boca Ratón, Florida, USA, 3rd edn, 2015.

25 M. G. Bellino, I. Tropper, H. Duran, A. E. Regazzoni and G. J. A. A. Soler-Illia, Small, 2010, 6, 1221.

26 M. G. Bellino and G. J. A. A. Soler-Illia, Small, 2014, 10, 2834.

27 J. D. Bass, D. Grosso, C. Boissiere, E. Belamie, T. Coradin and C. Sanchez, Chem. Mater., 2007, 19, 4349.

28 C. J. Brinker and G. W. Scherer, Sol-gel science: the physics and chemistry of sol-gel processing, Academic press, 2013.

29 D. H. W. Hubert, M. Jung, P. M. Frederik, P. H. H. Bomans, J. Meuldijk and A. L. German, Adv. Mater., 2000, 12, 1286.

30 S. Bégu, A. Aubert Pouëssel, D. A. Lerner, C. Tourné-Péteilh and J. M. Devoisselle, J. Controlled Release, 2007, 118, 1. 